\title{
GAMBARAN KEJADIAN POST PARTUM BLUES PADA IBU NIFAS DI KELURAHAN NANGGALO WILAYAH KERJA PUSKESMAS NANGGALO PADANG TAHUN 2018
}

\author{
Risnawati, Dewi Susilawati \\ STIKes MERCUBAKTIJAYA Padang \\ Email :_bidanrisna@gmail.com,dewisusilawati39@gmail.com
}

\begin{abstract}
ABSTRAK
Postpartum blues ini dikategorikan sebagai sindrom gangguan mental yang ringan. Oleh sebab itu, gangguan ini sering tidak dipedulikan bahkan sering anggap sebagai efek samping keletihan, sehingga tidak terdiagnosis dan tidak tertangani sebagaimana harusnya. Akhirnya dapat menjadi masalah yang menyulikan, tidak menyenangkan, dan dapat membuat perasaan-perasaan tidak nyaman bagi wanita yang mengalaminya. Diperkirakan 50-70\% ibu melahirkan menunjukkan gejala-gejala awal kemunculan post partum blues, walau demikian gejala tersebut dapat hilang secara perlahan karena proses adaptasi yang baik serta dukungan dari keluarga yang cukup. Penelitian ini bertujuan untuk mengetahui gambaran kejadian post partum blues pada ibu nifas.Jenis penelitian yang di gunakan adalah deskptif. Data yang di kumpulkan adalah data primer. Populasi dalam penelitian ini adalah seluruh ibu post partum pada hari ke 7 - 42 yang ada di Kelurahan kurao pagang wilayah kerja Puskesmas Nanggalo Kota Padang pada bulan bulan Juni berjumlah 19 orang. Penelitian ini telah dilaksanakan pada tanggal Juli 2018. Pengolahan data melalui tahap editing, coding, entry, tabulating dan cleaning yang dilakukan secara komputerisasi. Sedangkan analisis data secara univariat menggunakan distribusi frekuensi. Berdasarkan hasil penelitian didapatkan bahwa $15,8 \%$ responden memiliki umur beresiko, $89,5 \%$ memiliki pendidikan yang rendah, $73,7 \%$ responden tidak bekerja, $63,3 \%$ responden memiliki paritas multigravida dan $52,6 \%$ responden tidak mengalami kejadian post partum blues. Berdasarkan hasil penelitian didapatkan bahwa dari 19 responden maka dapat disimpulkan sebagai berikut lebih dari separoh responden memiliki umur tidak beresiko, berpendidikan rendah, tidak bekerja, memiliki paritas multigravida dan tidak mengalami kejadian post partum blues. Untuk diharapkan bagi tenaga kesehatan yang terkait dengan kesehatan ibu nifas harus semakin memperhatikan mengenai adaptasi psikologis ibu nifas.
\end{abstract}

\section{Kata Kunci : Postpartum Blues, EDPS (Edinburg Postnatal Depressiob Scale)}

\begin{abstract}
Postpartum blues is categorized as a mild mental disorder syndrome. Therefore, this disorder is often ignored and often even considers as a side effect of fatigue, so it is not diagnosed and not handled as it should. Finally, it can be a problem that is inciting, unpleasant, and can make uncomfortable feelings for the woman who experienced it. It is estimated that 50-70\% of mothers give birth to the early symptoms of the emergence of postpartum blues, although these symptoms can disappear slowly due to the process of good adaptation and support from sufficient families. This study aims to determine the incidence of post partum blues in postpartum mothers.The type of research used is descriptive. The data collected is primary data. The population in this study were all post partum mothers on days $3-42$ in Nanggalo Village, the working area of the Nanggalo City Health Center in Padang in June was 19 people. This research was carried out on July 2018. Data processing was done through the stages of editing, coding, entry, tabulating and cleaning which were carried out computerized. While the data analysis using univariate uses frequency distribution.Based on the results of the study found that $15.8 \%$ of respondents had a risky age, $89.5 \%$ had a low education, $73.7 \%$ of respondents did not work, $63.3 \%$ of respondents had multigravida parity and $52.6 \%$ of respondents did not experience post partum blues. Based on the results of the study found that of the 19 respondents it can be concluded as follows: more than half of the respondents had an age that was not at risk, had low education, did not work, had multigravida parity and did not experience the incidence of postpartum blues. To be expected for health workers related to postpartum maternal health should increasingly pay attention to the psychological adaptation of postpartum mothers. Keywords: Post partum blues, postpartum
\end{abstract}

Keyword: Postpartum, EDPS (Edinburg Postnatal Depressiob Scale) 


\section{PENDAHULUAN}

Post partum blues merupakan kesedihan ataukemurungan setelah melahirkan, biasanya hanya muncul sementara waktu, yakni sekitar dua hari hingga dua minggu sejak kelahiran bayi. Tanda dan gejalanya antara lain cemas tanpa sebab, menangis tanpa sebab, tidak sabar, tidak percaya diri, sensitif atau mudah tersinggung, serta merasa kurang menyayangi bayinya. Peningkatan dukungan mental atau dukungan keluarga sangat di perlukan dalam mengatasi gangguan psikologis yang berhubungan dengan masa nifas ini (Dahro, 2012) .

Angka kejadian post partum blues di luar negeri cukup tinggi mencapai $26-85 \%$. Secara global diperkirakan $20 \%$ wanita melahirkan menderita post partum blues. Di belanda tahun 2015 diperkirakan 2-10\% ibu melahirkan mengidap gangguan ini. Diperkirakan 50-70\% ibu melahirkan menunjukkan gejala-gejala awal kemunculan post partum blues, walau demikian gejala tersebut dapat hilang secara perlahan karena proses adaptasi yang baik serta dukungan dari keluarga yang cukup. Suatu penelitian di Negara yang pernah di lakukan seperti di Swedia, Australia, Italia dan Indononesia dengan menggunakan EDPS (Edinburg Postnatal Depressiob Scale) tahun 2017 menunjukkan $73 \%$ wanita mengalami post partum blues (Dahro. 2012).

Kaum wanita pada umumnya menganggap bahwa kehamilan adalah peristiwa kodrati yang harus dilalui tetapi sebagian wanita menganggap sebagai peristiwa khusus yang sangat menentukan kehidupan selanjutnya. Maka kualitas hidup manusia baik fisik dan psikologis wanita perlu dipertahankan. Penurunan psikologis dapat terjadi pada ibu post partum yaitu post partum blues. Post partum blues terjadi karena kurangnya dukungan terhadap penyesuaian yang dibutuhkan oleh wanita 18 dalam menghadapi aktifitas dan peran barunya sebagai ibu setelah melahirkan (Iskandar, 2013).

Hasil penelitian yang dilakukan oleh Irawati di DKI Jakarta menunjukkan 25\% dari 580 ibu yang menjadi respondennya mengalami sindroma ini. Dan dari beberapa penelitian yang telah dilakukan di Jakarta, Yogyakarta dan Surabaya, ditemukan bahwa angka kejadiannya 11$30 \%$, suatu jumlah yang tidak sedikit dan tidak mungkin dibiarkan begitu saja (Sylvia, 2016).

Hampir $80 \%$ wanita hamil mengalami serangan post partum blues setelah melahirkan bayi mereka, depresi pasca 
kelahiran merupakan masalah yang lebih serius. Menghinggapi kira-kira 10\% ibu baru, depresi ini lebih parah dan lebih kuat, serta bisa memengaruhi kemampuan merawat bayi. Wanita yang pernah mengalami depresi lebih rentan terhadap depresi, tanpa memandang usia atau jumlah kelahiran sebelumnya (Deepak, David, dkk, 2011)

Periode kehamilan dan melahirkan merupakan periode kehidupan yang penuh dengan potensi stres. Seorang wanita dalam periode kehamilan dan periode melahirkan (Post Partum) cenderung mengalami stres yang cukup besar karena keterbatasan kondisi fisik yang membuatnya harus membatasi aktivitas (Ambarwati, 2008).

Secara psikologis seorang ibu post partum akan melalui proses adaptasi psikologi semasa post partum (Sarwono, 2012). Dari kantor BKKBN provinsi Sumatera Barat di temukan data bahwa 7 dari 10 ibu yang melahirkan di provinsi Sumatera Barat pada tahun 2016 mengalami depresi berat setelah melahirkan, gejala depresi seperti tidak nafsu makan dan susah tidur merupakan keluhan yang paling sering di utarakan para ibu pasca melahirkan. (BKKBN, 2016).
Berdasarkan data Dinas Kesehatan Kota Padang tahun 2017 didapatkan jumlah sasaran ibu nifas sebanyak 17.602 orang. Dari 22 Puskesmas yang ada di Kota Padang jumlah sasaran ibu nifas terbanyak terdapat di Puskesmas Nanggalo yaitu sebanyak 2042 orang (11,6\%) (Dinkes Kota Padang, 2017). Menurut hasil pencapaian program kesehatan ibu Puskesmas Nanggalo Tahun 2017 didapatkan cakupan kunjungan ibu nifas (KF1) masih dibawah target yaitu 81,8\% sedangkan target yang ditetapkan adalah sebesar $90 \%$. Sementara dari 6 Kelurahan yang ada di wilayah kerja Puskesmas Nanggalo didapatkan cakupan kunjungan ibu nifas terendah di Kelurahan Kurao Pagang yaitu 68,8\% (Laporan Tahunan Puskesmas Nanggalo Padang, 2017).

Berdasarkan studi pendahuluan pada bulan Februari 2018 di Puskesmas Nanggalo Kota Padang didapatkan jumlah ibu post partum adalah 10 orang. 7 ibu post partum tidak mengalami post partum blues karena adanya dukungan keluaraga serta paritas dan umur yang cukup dan 3 ibu post partum mengalami post partum blues dengan alasan kurangnya dukungan keluarga yang kurang bersimpati pada keadaan ibu sebanyak 1 orang, dan dengan alasan paritas yang mempengaruhi dengan 
adanya anak pertama dan umur yang

terlalu muda sebanyak 2 orang.

Berdasarkan latar belakang diatas maka peneliti tertarik untuk melakukan penelitian tentang gambaran gambaran kejadian post partum blues pada ibu nifas di Kelurahan Nanggalo Wilayah Kerja Puskesmas Nanggalo Padang Tahun 2018.

\section{METODOLOGI}

Jenis penelitian yang di gunakan adalah deskptif. Data yang di kumpulkan adalah data primer. Populasi dalam penelitian ini adalah seluruh ibu post partum pada hari ke 7 - 42 yang ada di Kelurahan Nanggalo wilayah kerja Puskesmas Nanggalo Kota Padang pada bulan bulan Juni berjumlah 19 orang. Penelitian ini telah dilaksanakan pada tanggal Juli 2018. Pengolahan data melalui tahap editing, coding, entry, tabulating dan

cleaning yang dilakukan secara komputerisasi. Sedangkan analisis data secara univariat menggunakan distribusi frekuensi.

\section{HASIL DAN PEMBAHASAN}

\section{a. Umur}

\section{Tabel 1}

Distribusi Frekuensi Usia Ibu Nifas di Kelurahan Kurao Pagang Wilayah Kerja Puskesmas Nanggalo Kota Padang Tahun 2018

\begin{tabular}{|l|c|c|c|}
\hline No & Umur & $\begin{array}{c}\text { Frekuensi } \\
(\mathbf{f})\end{array}$ & $\begin{array}{c}\text { Pernsentase } \\
(\mathbf{\%})\end{array}$ \\
\hline 1. & Beresiko & 3 & 15,8 \\
\hline 2. & $\begin{array}{c}\text { Tidak } \\
\text { Beresiko }\end{array}$ & 16 & 84,2 \\
\hline \multicolumn{2}{|c|}{ Jumlah } & 19 & 100,0 \\
\hline
\end{tabular}

Berdasarkan hasil penelitian didapatkan didapatkan sebanyak 3 orang $(15,8 \%)$ responden memiliki usia beresiko dan 16 orang $(84,2 \%)$ responden memiliki usia tidak beresiko.

Adapun persentase kejadian postpartum blues yang didapatkan pada usia yang beresiko $(<20$ dan $>35$ tahun $)$ adalah berjumlah 2 orang $(10,5 \%)$ dan tidak sebanyak 1 orang $(5,2 \%)$. Hal ini menunjukkan bahwa persentase usia yang beresiko yaitu usia $<20$ tahun atau $>35$ tahun lebih sedikit dibandingkan umur yang tidak beresiko. Penelitian ini tidak sesuai dengan pendapat Bobak (2005), bahwa factor pencetus terjadinya $\mathrm{p}$ ostpartum blues adalah pada usia remaja atau kurang dari 20 tahun. Kehamilan dan persalinan pada remaja menjadi salah satu faktor pendukung terjadinya postpartum blues. Penyebab lain postpartum blues selain usia persalinan dibawah usia 20 
tahun adalah kesiapan remaja dalam perubahan perannya sebagai ibu, antara lain: kesiapan fisik, mental, finansial dan sosial (Henshaw C, 2007).

Melahirkan di bawah usia 20 tahun menyebabkan kurangnya kematangan

dalam berpikir, sehingga akan menyebabkan kurang siapnya mental seseorang dalam mengurus anak dan rumah tangga (Ambarwati, 2008).

Hal ini sesuai dengan penelitian yang dilakukan Fitriana Lisna (2015) bahwa usia tidak berpengaruh dengan kejadian postpartum blues, kejadian post partum blues pada usia yang beresiko terdapat $30 \%$ mengalami post partum blues, dan usia tidak beresiko terdapat $70 \%$ mengalami postpartum blues dikarenakan ada aspek lain yang mempengaruhi terjadinya postpartum blues, dan tingkat kedewasaan orang tidak dapat ditentukan dengan umur saja.

\section{b. Pendidikan}

Tabel 2

\begin{tabular}{|c|c|c|c|}
\hline $\begin{array}{r}\text { Distr } \\
\text { Nifa } \\
\text { Wila }\end{array}$ & $\begin{array}{l}\text { usi Frekue } \\
\text { di Kelurah } \\
\text { h Kerja Pu } \\
\text { cota Padang }\end{array}$ & $\begin{array}{l}\text { si Pendid } \\
\text { n Kurao } \\
\text { kesmas } \\
\text { Tahun } 20\end{array}$ & $\begin{array}{l}\text { kan Ibu } \\
\text { 'agang } \\
\text { anggalo } \\
18\end{array}$ \\
\hline No & Pendidikan & $\begin{array}{c}\text { Frekuensi } \\
\text { (f) }\end{array}$ & $\begin{array}{c}\text { Pernsentase } \\
(\%)\end{array}$ \\
\hline 1. & Tinggi & 2 & 10,5 \\
\hline 2. & Rendah & 17 & 89,5 \\
\hline & umlah & 19 & 19 \\
\hline
\end{tabular}

Berdasarkan hasil penelitian didapatkan bahwa dari 19 responden didapatkan sebanyak 17 orang $(89,5 \%)$ memiliki pendidikan yang rendah dan 2 orang $(10,5 \%)$ yang berpendidikan tinggi.

Adapun persentase kejadian postpartum blues yang didapatkan pada tingkat pendidikan ibu yang rendah adalah berjumlah 9 orang $(47,3 \%)$. Hal ini disebabkan karena kurangnya pengetahuan yang dimiliki ibu yang berpendidikan rendah. Didukung oleh teori Hunker (2007) mengemukakan postpartum blues yang dialami wanita setelah melahirkan juga disebabkan kurangnya pengetahuan wanita yang baru melahirkan terhadap tugas-tugas baru yang harus dijalani sebagai seorang ibu. Hasil penelitian ini sebanding dengan penelitian sebelumnya yang dilakukan oleh Fatmawati (2015) di Puskesmas Wilayah Kerja Kota Yogyakarta, menemukan $76 \%$ responden memiliki status pendidikan yang rendah.

Persentase kejadian post partum blues yang didapatkan pada tingkat pendidikan ibu yang tinggi adalah berjumlah 1 orang $(5,3 \%)$. Hal ini kemungkinan disebabkan karena tingkat pendidikan formal ibu tidak mempengaruhi pengetahuannya. Menurut (Notoatmojo, 2007) Pendidikan berarti bimbingan yang diberikan seseorang terhadap perkembangan orang lain menuju kearah suatu cita-cita tertentu. Kegiatan pendidikan formal maupun informal 
berfokus pada proses belajar mengajar, dengan tujuan agar terjadi perubahan perilaku yaitu dari tidak tahu menjadi tahu, dari tidak mengerti menjadi mengerti, dan dari tidak dapat menjadi dapat. Maka makin tinggi pendidikan seseorang makin mudah menerima informasi sehingga makin banyak pula pengetahuan yang dimiliki.

\section{c. Pekerjaan}

Tabel 3

Distribusi Frekuensi Pekerjaan Ibu

Nifas di Kelurahan Kurao Pagang

Wilayah Kerja Puskesmas Nanggalo Kota Padang Tahun 2018

\begin{tabular}{|l|c|c|c|}
\hline No. & Pekerjaan & $\begin{array}{c}\text { Frekuensi } \\
\text { (f) }\end{array}$ & $\begin{array}{c}\text { Pernsentase } \\
(\mathbf{\%})\end{array}$ \\
\hline 1. & Bekerja & 5 & 26,3 \\
\hline 2. & $\begin{array}{c}\text { Tidak } \\
\text { Bekerja }\end{array}$ & 17 & 73,3 \\
\hline \multicolumn{2}{|c|}{ Jumlah } & 19 & 100,0 \\
\hline
\end{tabular}

Berdasarkan hasil penelitian didapatkan bahwa dari 19 responden didapatkan sebanyak 5 orang $(26,3 \%)$ responden bekerja. Menurut asumsi peneliti bahwa mengidenfikasi ibu bedasarkan pekerjaan dapat dilihat bahwa kejadian Post Partum Blues lebih banyak terjadi pada ibu yang tidak bekerja. Menurut Thomas yang dikutip oleh Nursalam (2013), bekerja umumnya merupakan kegiatan yang menyita waktu, dan bekerja bagi ibu-ibu akan mempunyai pengaruh terhadap kehidupan keluarga. Dilihat dari tingkat pendidikan responden yang terbanyak bekerja sebagai ibu rumah tangga yaitu mempunyai pendidikan SMA. Dalam penelitian ini ibu yang bekerja sebagai ibu rumah tangga lebih banyak mengalami Post Partum Blues, hal ini tidak sesuai dengan teori yang mengatakan dengan bekerja ibu mempunyai pengaruh dan lebih banyak mendapat informasi hal ini karena terdapat faktor yang mempengaruhi seperti pengalaman dan melahirkan sebelumnya dan informasi dari media massa serta lingkungan sosial budaya. Hasil penelitian ini sebanding dengan penelitian sebelumnya yang dilakukan oleh Fitriana Lisna (2015) di Rumah Sakit Umum Tingkat IV Sariningsih Kota Bandung, menemukan $40 \%$ responden memiliki status pekerjaan.

Penelitian ini menunjukkan kejadian postpartum blues terjadi pada sebagian besar ibu postpartum yang tidak bekerja atau ibu rumah tangga yaitu sebanyak 9 orang responden. Hal ini sejalan dengan pendapat Ambarwati (2008), menyatakan bahwa ibu-ibu yang hanya bekerja dirumah mengurusi anak-anak mereka dapat mengalami keadaan krisis situasi dan mencapai gangguan perasaan/blues karena rasa lelah dan letih yang mereka rasakan. Pada ibu rumah tangga yang mengurusi semua urusan rumah tangga sendiri, kemungkinan mempunyai tekanan terhadap tanggung jawabnya baik sebagai istri atau sebagai seorang ibu. 
Berbeda dengan penelitian yang dilakukan Anoraga (2009), mengemukakan bahwa wanita pekerja lebih banyak akan kembali pada rutinitas bekerja setelah melahirkan dan cenderung memiliki peran ganda yang menimbulkan gangguan emosional. Wanita yang bekerja dapat mengalami postpartum blues disebabkan adanya konflik peran ganda yang menimbulkan masalah baru bagi wanita tersebut (Jadri et al., 2006). Wanita yang bekerja merasa mempunyai tanggung jawab yang lebih besar dalam rumah tangga yaitu sebagai seorang istri dan seorang ibu yang juga memiliki tanggung jawab dalam pekerjaannya

\section{d. Paritas}

\section{Tabel 4}

\section{Distribusi Frekuensi Usia Ibu Nifas di Kelurahan Kurao Pagang Wilayah Kerja Puskesmas Nanggalo Kota Padang Tahun 2018}

\begin{tabular}{|l|l|c|c|}
\hline No & Paritas & $\begin{array}{c}\text { Frekuensi } \\
(\mathbf{f})\end{array}$ & $\begin{array}{c}\text { Pernsentase } \\
(\mathbf{\%})\end{array}$ \\
\hline 1. & Primigravida & 7 & 36,8 \\
\hline 2. & Multigravida & 12 & 63,2 \\
\hline & Jumlah & 19 & 100,0 \\
\hline
\end{tabular}

Berdasarkan hasil penelitian didapatkan bahwa dari 19 responden didapatkan lebih dari separoh yaitu sebanyak 12 orang $(63,2 \%)$ responden memiliki paritas multigravida. Menurut asumsi peneliti hasil penelitian menunjukkan bahwa ibu postpartum yang terjadi postpartum blues pada primigravida sebanyak sebanyak 6 orang $(31,5 \%)$. Hal ini disebabkan karena faktor-faktor yang mempengaruhui postpartum blues yaitu : faktor yang pertama konstitual gangguan post partum berkaitan dengan status paritas adalah riwayat obstetri pasien yang meliputi riwayat hamil sampai bersalin serta apakah ada komplikasi dari kehamilan dan persalinan sebelumnya dan terjadi lebih banyak pada wanita primipara. Wanita primipara lebih umum menderita blues karena setelah melahirkan wanita primipara berada dalam proses adaptasi, kalau dulu hanya memikirkan diri sendiri begitu bayi lahir jika ibu tidak paham perannya ia akan menjadi bingung sementara bayinya harus tetap dirawat.

Penelitian ini menunjukkan bahwa kejadian postpartum blues paling banyak terjadi pada ibu primipara yaitu sebanyak 6 orang responden. Hasil penelitian menunjukkan bahwa ibu primipara mempunyai peluang lebih besar untuk mengalami postpartum blues dibandingkan dengan ibu multipara. Hasil penelitian ini sesuai dengan pendapat Deal \& Holt (1998), mengemukakan postpartum blues banyak terjadi pada ibu primipara. Wanita primipara baru memasuki perannya sebagai seorang ibu, tetapi tidak menutup kemungkinan terjadi pada ibu yang pernah 
melahirkan, yaitu jika ibu mempunyai riwayat postpartum blues sebelumnya.

Faktor kedua psikologis peralihan yang cepat dari keadaan "dua dalam satu" pada akhir kehamilan menjadi dua individu yaitu ibu dan anak bergantung pada penyesuaian psikologis individu. Klaus dan Kennel mengindikasikan pentingnya cinta dalam menanggulangi masa peralihan ini untuk memulai hubungan baik antara ibu dan anak. Faktor yang ketiga social menurut Paykel mengemukakan bahwa pemukiman yang tidak memadai lebih sering menimbulkan depresi pada ibu - ibu, selain kurangnya dukungan dalam perkawinan (Regina dkk. 2001). Penelitian ini sejalan dengan penelitian yang dilakukan Sabrian dkk (2014) didapatkan bahwa paritas yang terbanyak adalah multipara dengan jumlah 32 orang ibu postpartum $(57,1 \%)$.

Hasil penelitian ini juga sesuai dengan penelitian O’Hara (1996) yang menyatakan bahwa kelahiran anak pertama menunjukkan stres dan berhubungan dengan kejadian postpartum blues yang lebih kuat dibandingkan dengan kelahiran anak kedua atau ketiga. Wanita primipara belum mempunyai pengalaman dalam merawat anak sehingga timbul rasa takut dan khawatir melakukan kesalahan dalam merawat bayi. Begitu pula dalam melakukan tugas sebagai seorang ibu, wanita primipara merasa bingung, lebih terbebani dan merasa kebebasannya berkurang dengan hadirnya seorang anak.

Hasil penelitian ini juga sejalan dengan pendapat Mansur menyatakan bahwa kejadian postpartum blues sering dialami oleh ibu yang baru pertama kali melahirkan karena hal ini berhubungan dengan kemampuan atau pengalaman ibu dalam menghadapi masalah-masalah yang terjadi dalam merawat bayi. Ibu yang belum berpengalaman akan memberikan dampak terhadap perawatan yang diberikan kepada bayinya. Pengetahuan ibu juga mempunyai pengaruh besar terhadap perawatan yang dilakukan kepada anaknya.

\section{e. Kejadian Post Partum Blues}

Tabel 5

Distribusi Frekuensi Kejadian Post

Partum Blues Ibu Nifas di Kelurahan

Kurao Pagang Wilayah Kerja

Puskesmas Nanggalo Kota

Padang Tahun 2018

\begin{tabular}{|l|c|c|c|}
\hline No. & $\begin{array}{c}\text { Kejadian Post } \\
\text { Partum Blues }\end{array}$ & $\begin{array}{c}\text { Frekuensi } \\
(\mathbf{f})\end{array}$ & $\begin{array}{c}\text { Pernsentase } \\
(\boldsymbol{\%})\end{array}$ \\
\hline 1. & $\begin{array}{c}\text { Tidak post } \\
\text { partum blues }\end{array}$ & 9 & 47,4 \\
\hline 2. & $\begin{array}{c}\text { Post partum } \\
\text { blues }\end{array}$ & 10 & 52,6 \\
\hline \multicolumn{2}{|l}{ Jumlah } & 19 & 100,0 \\
\hline
\end{tabular}

Berdasarkan hasil penelitian didapatkan bahwa dari 23 responden didapatkan sebanyak 10 orang $(52,6 \%)$ responden 
mengalami kejadian post partum blues. Sedangkan gejala post partum blues yang sering dialami responden adalah tidak mampu tertawa dan merasakan hal-hal yang menyenangkan dan tidak pernah melihat segala sesuatunya kedepan sangat menyenangkan.

Penyebab terjadi post partum blues pada penelitian ini kemungkinan disebabkan karena kurangnya dukungan sosial dari keluarga merupakan penyebab terjadinya masalah emosional pada periode postpartum. Untuk itu pada ibu post partumperlu diberikan dukungan baik secara psikologis, material maupun instrumental agar mampu melalui masa pst partum dengan baik. Hal itu bisa dilakukan dengan cara membantu ibu baru menyesuaikan diri secara positif dan sehat untuk peran baru mereka, tanggung jawab, dan identitas sebagai ibu. Memberikan waktu istirahat yang cukup, memenuhi kebutuhannya dan melibatkan keluarga, atau suami dalam merawat bayi akan mengurangi masalah emosianal ibu yang bisa menyebabkan post partum blues. Bagi tenaga kesehatan pentingnya memberikan informasi tentang tanda dan karakteristik postpartum blues, memberikan health education tentang perawatan ibu setelah melahirkan dan cara merawat bayi bisa mengurangi kecemasan ibu yang bisa menyebabkan terjadinya postpartum blues (Griffin K, Martin, Reeder, 2011).

Penelitian juga ini sejalan dengan penelitian yang dilakukan oleh Fatimah (2009) di Ruang Bugenvile RSUD Tugurejo Semarang menunjukkan bahwa 11 orang sebanyak (44\%) menunjukkan terjadi gejala Postpartum Blues. Untuk melengkapi data tentang postpartum blues peneliti melakukan wawancara kepada responden. Berdasarkan hasil wawancara, paritas merupakan salah satu faktor yang mempengaruhi seorang ibu bersalin mengalami postpartum blues, selain itu ibu yang mengalami postpartum blues juga merasa bahwa dirinya belum siap dalam mengurus anaknya.

Berdasarkan penelitian yang dilakukan, sebagian besar responden yang mengalami post partum blues menjawab kelelahan dalam mengurus anaknya, selain itu ada juga responden yang menjawab cemas dengan keadaannya terutama dalam mengurus anaknya merasa belum bisa memberikan yang terbaik selain itu ada juga responden yang mengalami susah tidur karena terbebani oleh kelahiran bayinya, ada juga responden mengalami gelisah karena kepikiran anaknya, ada juga responden mengalami binggung 
dalam mengurus anaknya terutama saat menangis binggung harus bagaimana, mengalami lupa atas kelahiran anaknya sehingga menyebabkan postpartum blues. Kehamilan dan persalinan pada remaja menjadi salah satu faktor pendukung terjadinya postpartum blues.

Penyebab lain postpartum blues selain usia persalinan dibawah usia 20 tahun adalah kesiapan remaja dalam perubahan perannya sebagai ibu, antara lain: kesiapan fisik, mental, finansial dan sosial (Henshaw, 2007). Melahirkan di bawah usia 20 tahun menyebabkan kurangnya kematangan dalam berpikir, sehingga akan menyebabkan kurang siapnya mental seseorang dalam mengurus anak dan rumah tangga. Dalam kurun reproduksi sehat dikenal bahwa usia aman untuk kehamilan dan persalinan adalah 20-30 tahun.

Hasil penelitian yang dilakukan didapatkan hasil bahwa sebagian besar responden berusia beresiko tidak mengalami postpartum blues karena mendapatkan dukungan sosial dari keluarga terutama dari suami. Adanya dukungan sosial membuat responden dapat mengatasinya dan melewati masa postpartum blues dengan waktu yang singkat. Hal ini didukung Urbayatun Siti (2010) yang menyebutkan bahwa dukungan sosial berhubungan negatif dengan kecenderungan depresi postpartum pada ibu primipara.

\section{KESIMPULAN}

Hampir semuanya responden memiliki usia tidak beresiko yaitu sebanyak $84,2 \%$, hampir semuanya responden memiliki pendidikan yang rendah tentang postpartum blues yaitu sebanyak $89,5 \%$, lebih dari separuh responden tidak bekerja yaitu sebanyak $73,3 \%$, lebih dari separuh responden memiliki paritas multigravida yaitu sebanyak $63,2 \%$, lebih dari separuh responden mengalami depresi postpartum blues yaitu sebanyak $52,6 \%$

\section{KEPUSTAKAAN}

Anoraga. (2009). Psikologi Kerja. Jakarta: PT. Rineka Cipta

Ambarwati. (2008) Konsep Kebutuhan Dasar Manusia. Yogyakarta: Dua Satria Offset

Bobak dkk. (2005) Buku Ajar keperawatan maternitas Edisi 4. Jakarta: EGC

BKKBN. (2016). Pemantauan Pasangan Usia Subur Melalui Mini Survei. Indonesia. Jakarta

Deepak, David, dkk. (2011). Terapi Musik Terhadap Pencegahan PostpartumBlues Pada Ibu
primipara
Di Ruang
Kebidanan RSUP Cipto angunkusumo Jakarta Pusat.

Dahro. (2012). Buku Psikologi Kebidanan analisis perilaku wanita untuk kesehatan,Salemba Medika, Jakarta.

Deal L \& Holt V. (1998). Young Maternal Age and Depresssive Symtoms : esult from the 1988 National Maternal and Infant Health Survey. Bureu of Maternal and Child 
Health. Am J Public Health, 88(2): 266-270

Fatimah. (2009). Hubungan Dukungan Suami dengan Kejadian Postpartum Blues pada ibu primipara di Ruang Bugenvile RSUD Tugurejo Semarang. Universitas Dipanegoro Fatmawati, (2015). Faktor Risiko Yang Berpengaruh Terhadap Kejadian Postpartum. Jurnal Edu Health, Vol. 5 No. 2

Fitriana Lisna. (2015). Gambaran Kejadian Post Partum Blues Pada Ibu Nifas Berdasarkan Karakteristik di Rumah Sakit Umum Tingkat IV Saringsih Kota Bandung. Jurnal Keperawatan. Jakarta : Fakultas Pendidikan Indonesia.

Griffin, K, Martin, Reeder. (2011). Keperawatan Maternitas (volume 2) Buku Kedokteran. Jakarta: EGC

Henshaw, Corol. (2007). PMS : Diagnosis, Etiology, Assesment and Management, Advance in Psychiatric Treatment.

Iskandar. (2013). Asuhan Keperawatan Jiwa. Bandung : Refika. Aditama

Jadri et al. (2006). Predictive Validation Study of the Edinburg Postnatal Depression Scale in the First Week after Delivery and Risk Analysis for Posnatal Depression. Journal of Affective Disorder, 93:69-176

Laporan Tahunan Puskesmas Nanggalo Padang. (2017).

Mansur. (2009). Psikologis Ibu dan Anak. Jakarta : Salemba Medika

Notoatmodjo, S. (2010). Metodologi Penelitian Kesehatan. Rineka Cipta. Jakarta

Nursalam. (2013). Manajemen Keperawatan: Aplikasi Dalam Praktik Keperawatan Profesional. Jakarta: Salemba Medika

O'Hara, M. (1996). Rates \& Risk of Postpartum Depression- metaanalysis. International Review of Psychiatry, 8, 37-54

Sylvia. (2016). Patofisiologi : Konsep Klinis Proses-proses Penyakit, Edisi 6, (terjemahan), Peter Anugrah, EGC, Jakarta

Sarwono. (2012). Psikologi Remaja. Jakarta: PT. Raja Grafindo. Persada

Urbayatum Siti. (2010). Gambaran Tingkat Depresi postpartum pada ibu primipara di daerah gempa bantul. Humanitas Jurnal Psikologi Indonesia. 7(2), 114 